\title{
ECOLOGICAL STUDIES ON PHLEBOTOMINAE (DIPTERA:PSYCHODIDAE) IN AN URBAN AREA OF THE CITY OF CAMPO GRANDE, MATO GROSSO DO SUL STATE, BRAZIL
}

Thesis: A. G. Oliveira submitted this thesis for her Doctorate in Parasite Biology at the Instituto Oswaldo Cruz, FIOCRUZ, Rio de Janeiro, Rio de Janeiro State, Brazil, 2006.

Advisor: Professor Eunice Aparecida Bianchi Galati.

Co-advisor: Professor Reginaldo Peçanha Brazil.

ABSTRACT: The ecological aspects of sand flies in the city of Campo Grande, Mato Grosso do Sul State, Brazil, were studied. Insects were weekly captured using CDC light traps from December 2003 to November 2005 at seven different places within forestal and residential areas. Twenty-five species of sand flies out of 11,024 specimens (7,805 males and 3,219 females) were captured. From these specimens, 9,963 (90.38\%) were Lutzomyia longipalpis, a vector of visceral leishmaniasis. It was the most prevalent and abundant in all the studied area. In forestal areas, other species that are known vectors of cutaneous leishmaniasis were captured: Nyssomyia whitmani, Nyssomyia antunesi and Bichromomyia flaviscutellata. With regard to seasonal distribution, Lutzomyia longipalpis was found throughout the year with small peaks every 2 to 3 months and high peaks after the rainy season. The maximum dispersion distance was $100 \mathrm{~m}$ for males and $50 \mathrm{~m}$ for females; $99.4 \%$ was recaptured in the same release area and $0.6 \%$, up to $100 \mathrm{~m}$ apart. In relation to feeding habits, 327 out of 355 females studied were Lutzomyia longipalpis and $66.4 \%$ of them presented human blood, $64.8 \%$ bird blood and only $8.9 \%$ dog blood. In all residential areas and in two forestal areas, human blood was predominant. Studies on natural infection by Leishmania showed that nine sand flies were positive, four Lutzomyia longipalpis and five other species: Evandromyia lenti, Micropygomyia quinquefer, Nyssomyia whitmani, Psathyromyia aragaoi and Psychodopygus claustrei, with a minimum infection rate (1.6\%). Results were useful to better understand the epidemiological situation of visceral leishmaniasis in Campo Grande.

KEY WORDS: Psychodidae, Campo Grande (MS), anatomy and histology, infection, Phlebotominae, Lutzomyia longipalpis, visceral leishmaniasis.

\section{CORRESPONDENCE TO:}

ALESSANDRA GUTIERREZ DE OLIVEIRA, Departamento de Patologia, Universidade Federal de Mato Grosso do Sul, Caixa Postal: 549, 79070-900, Campo Grande, MS, Brasil. Phones: 556733457390 and 556733457369 . Email: agoliveira@nin.ufms.br. 